\title{
Mini Mobile Telemetry System Application
}

\author{
Serdar ÇORA ${ }^{1}$, Mahmut Kürșad ARPACIOĞLU1', Hakan ESER ${ }^{1}$ \\ 1 TAI - Turkish Aerospace Industries, Inc., Fethiye Mahallesi, Havacilik Bulvari No: 17, 06980 Kazan- \\ ANKARA / TURKEY, \\ scora@tai.com.tr,mkarpacioglu@tai.com.tr, heser@tai.com.tr
}

\begin{abstract}
:
Mini Mobile Telemetry System is a ruggedized pc with three screens which the receiver board, the decommutator board and the GPS time generator board has placed in. Customized panels are used for RF, GPS signal inputs and serial data outputs for the flexible operational usage of the system. Various types of antennas are used for different operational scenarios.

Mini Mobile Telemetry System which is designed and configured for special needs of TAl Turkish Aerospace Industries Inc., serves for three main purposes.

The first purpose of the system is to serve such a portable telemetry station which one person could transport, install and operate on field easily. System could support up to three flight test engineers with customized displays which could be enough for a low risk test flight without occupying huge telemetry ground station.

The second purpose of the system is to have the chance for to be fixed in a mid-size A/C such a flying test bed. The real time visualization of data which is gathered from the vehicle under test during a flight test is possible. There will be no problem about the target range in reasonable ranges and LOS on the $\mathrm{A} / \mathrm{C}$ that chase the vehicle under test with proper antenna installation.

The third purpose of the system is to serve such a flying relay station for scenarios that LOS or range limits between ground station and vehicle under test could not be achieved. Such maneuvers performed at low altitude or out of range for receiving antenna on ground could be examples.
\end{abstract}

Key words: Telemetry, Mobile, Flying Test Bed, Flight Test, Instrumentation.

\section{System Description}

Mini Mobile Telemetry System is a ruggedized pc with three displays which the receiver board, the decommutator board and the GPS time code generator board has placed in. Customized panels are used for RF, GPS signal inputs and serial data input/outputs for flexible operational usage of the system.

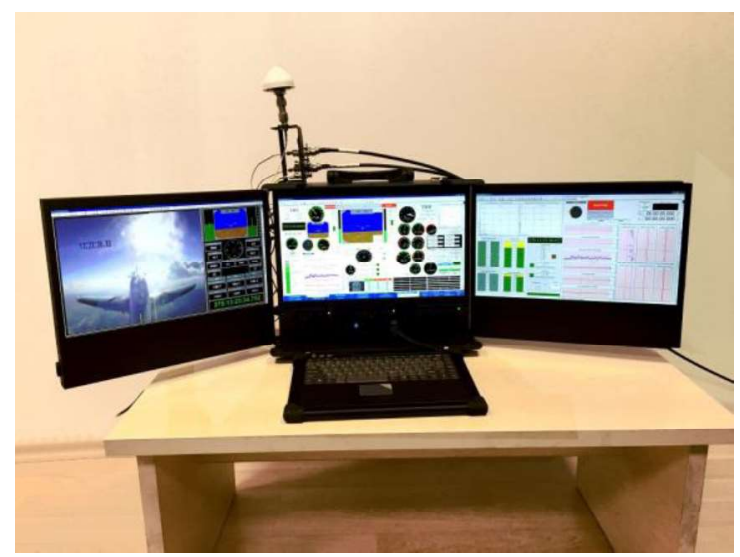

Fig. 1. Mini Mobile Telemetry System

\begin{abstract}
Aim for Designing such a System
Main purpose for such a design is to have the ability of using a telemetry system for flight tests under flexible conditions. Mini Mobile Telemetry System could be used on ground and on air for so many test scenarios which could be performed in close ranges on ground and onboard. The range of the relay operation purposes is limited with the capabilities of the telemetry system on ground. IRIG-106 standards were considered during system design and operation.
\end{abstract}

\section{System Components}

A ruggedized $\mathrm{pc}$ is used to assemble the system components. Main consideration was to be able to use multiple displays and to meet the system components power requirements.

A dual channel receiver board is chosen which has the proper sensitivity and dynamic range levels. A Decommutator Board is chosen which is compatible with the FTI data acquisition units. A GPS Time Code Generator board is used to generate the IRIG-B time code which has to be inserted to decommutator board so gathered 
data packets will be marked with the precise time tag. Real Time Data Analysis Software is used to monitor the flight test parameters in real time. In-house designed gauges and displays are used in Test Monitoring Displays.

The Interconnection Panel is designed to establish and operate required antenna and other signal connections easily. The interconnection panel protects the neat connectors and cable assemblies on pci boards.

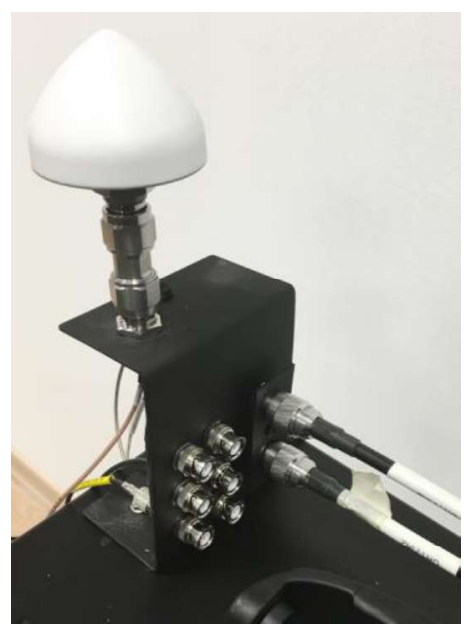

Figure 2 The Interconnection Panel

The Interconnection Panel also has the input and output signal connections for the decommutator board. Low loss adapters have been chosen which supports the certain frequency band for the application.

\section{Instrumented Aircraft}

The Mini Mobile Telemetry System has been used on flight tests of Turkish Primary and Basic Trainer, 'HURKUS' Project. The project has two prototype aircrafts and both of them are instrumented for flight test purposes. Telemetry transmitters are placed onboard for real time data acquisition in telemetry ground stations.

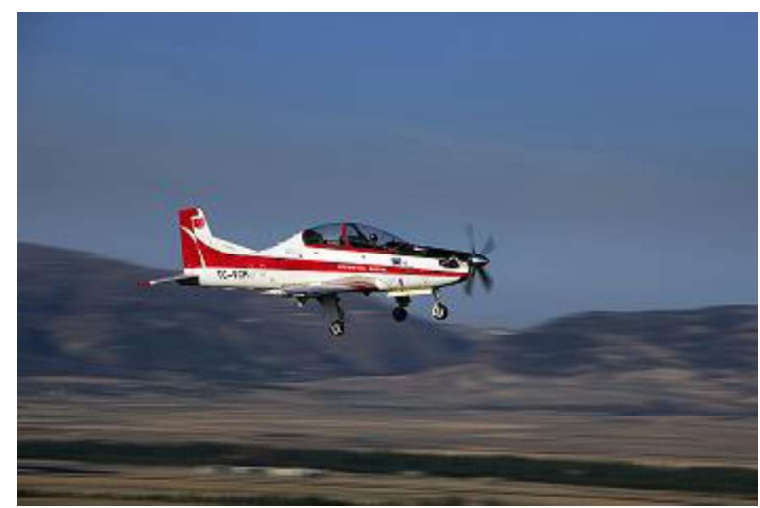

Figure 3 Turkish Primary and Basic Trainer, 'HURKUS'
Antenna locations on prototype aircrafts were decided after the propagation of antennas were analyzed via a software. The software uses the antenna specific information that are supplied by the manufacturer. A 3D model of the platform which antennas placed on used to simulate the radiation patterns and power levels due to distance of the receiver antenna.

Images of the analysis which have performed are given below. The horizontal bar graph indicates the power level between $-240 \mathrm{dBm}$ to $-10 \mathrm{dBm}$.

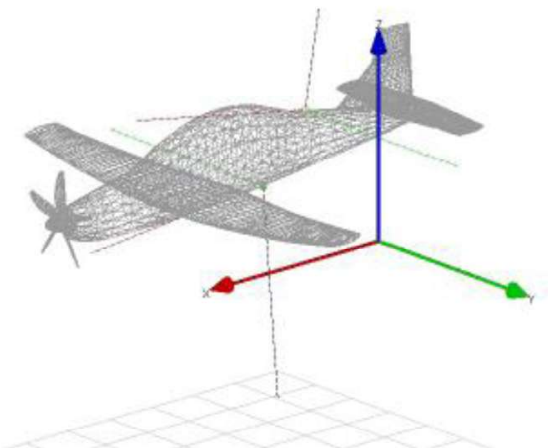

Figure 4 Antenna Placement on HURKUS Aircraft

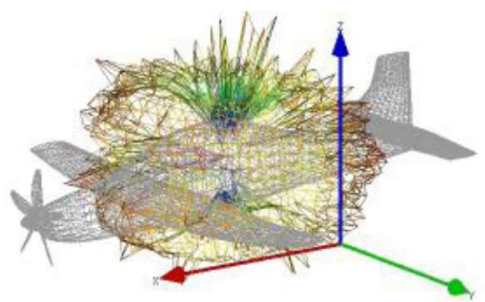

Figure 5 Farezone Analysis

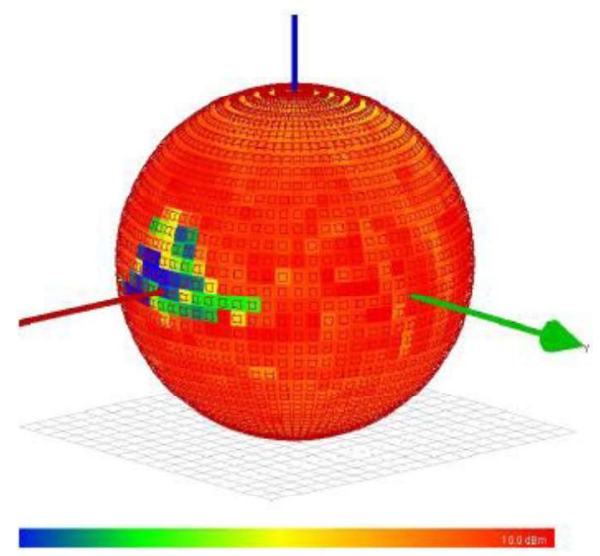

Figure 6 Total Power Analysis

\section{System Operation Scenarios}

First option for the system is to serve on ground for up to three flight test engineers during close range flight tests. The system has been operated during Turkish Primary and Basic 
Trainer, 'HURKUS' Project flight test campaign. The comments of flight test engineers for the Mini Mobile Telemetry system was 'satisfactory'. A VHF radio was used by the lead flight test engineer to communicate with the test pilot. Each flight test engineer used one 'test specific designed' display to follow the requested parameters during flight tests. Some sample display figures are given below.

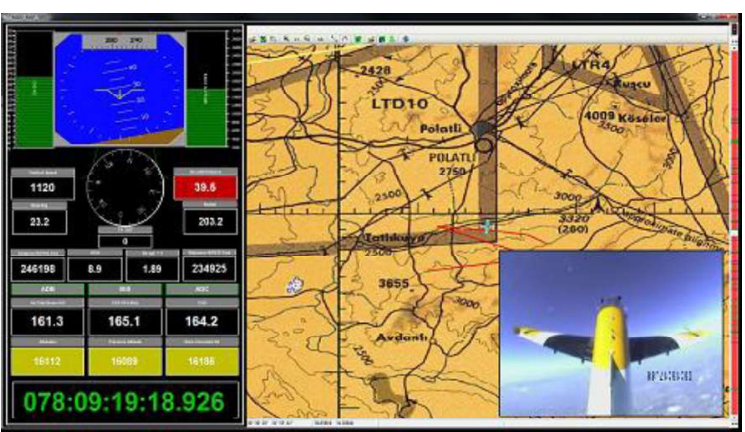

Figure 7 Test Monitoring Screen \# 1

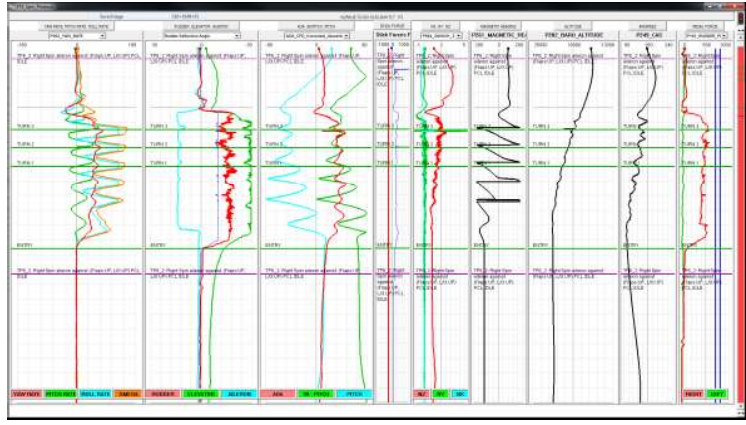

Figure 8 Test Monitoring Screen \# 2

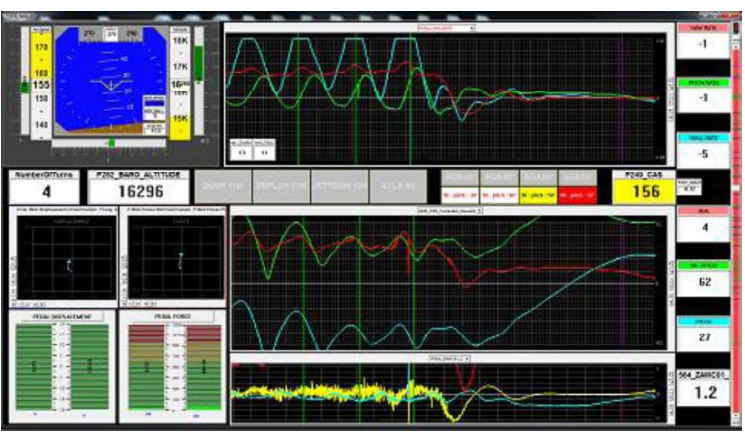

Figure 9 Test Monitoring Screen \# 3

For flight test operations conducted on ground, Mini Mobile Telemetry System could be placed anywhere on ground within the limitations of line of sight and range. One GPS antenna and Two receiving (omni-directional | LHCP, RHCP) antennas are used with LNAs mounted on tripods on ground. Antenna connections were made using the interconnection panel.

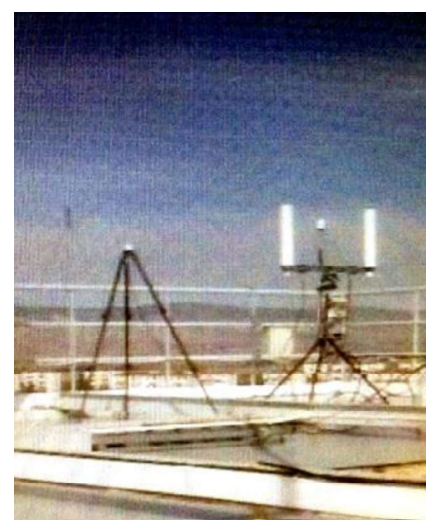

Figure 10 Receiving Antennas (LHCP \& RHCP) and GPS Antenna

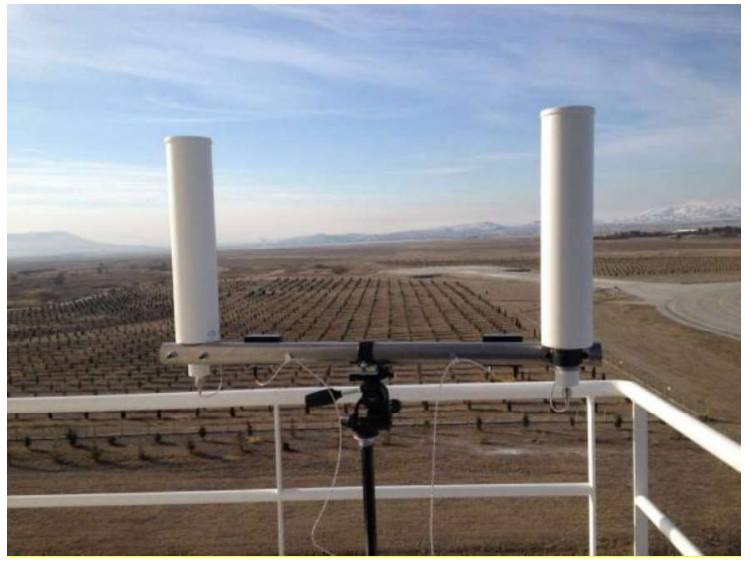

Figure 11 Receiving Antennas (LHCP \& RHCP)

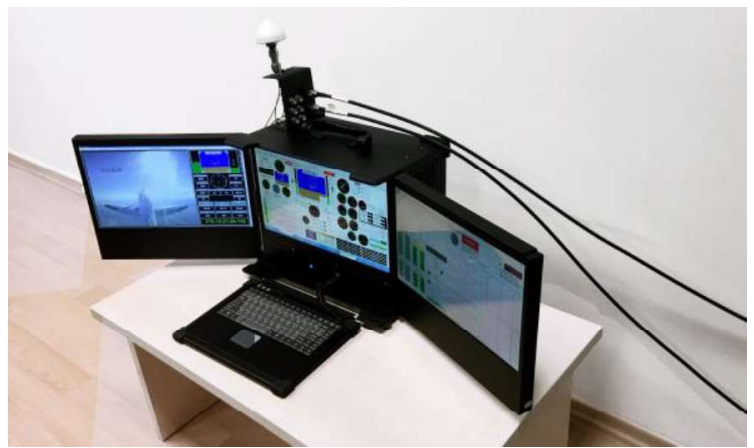

Figure 12 Mini Mobile Telemetry System

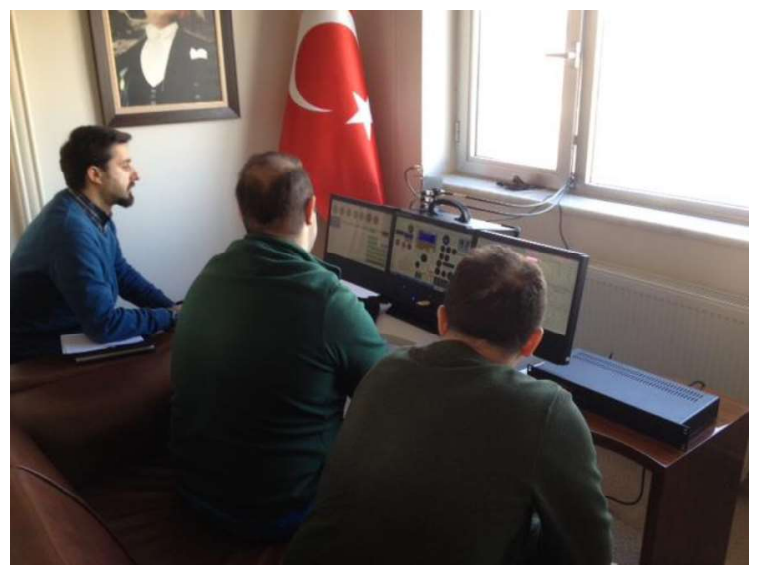

Figure 13 Mini Mobile Telemetry System in Operation 
The system architecture for on ground operations is given below.

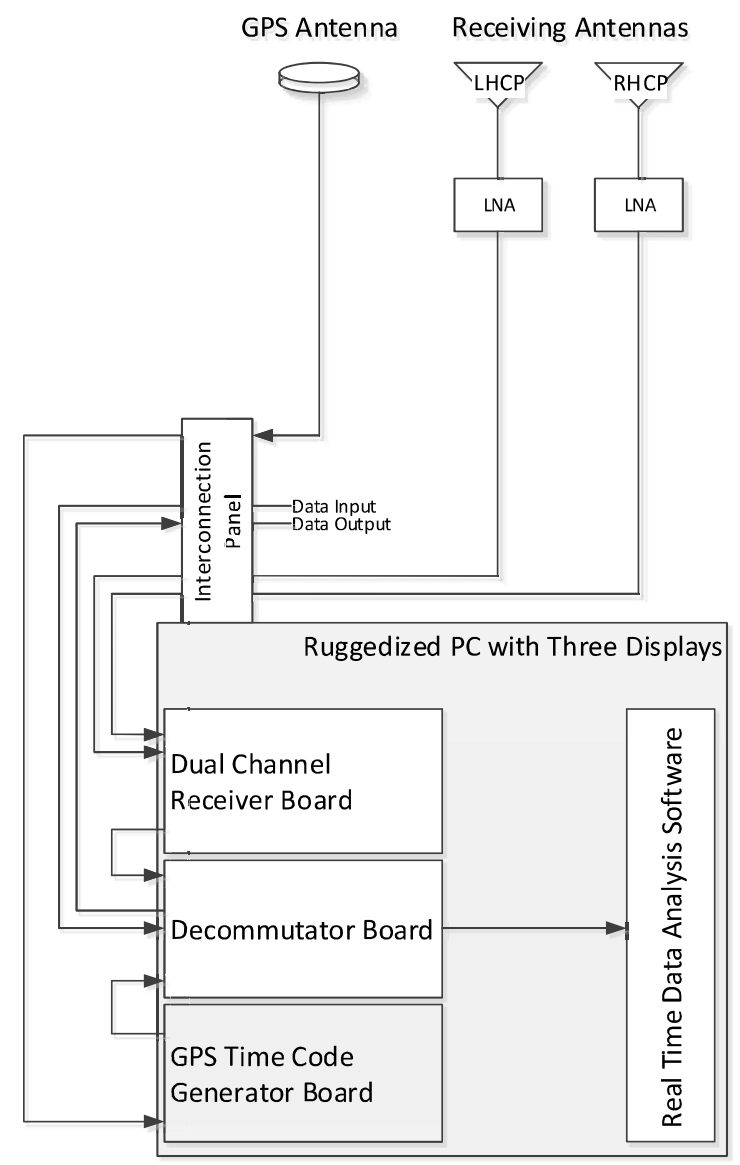

Figure 14 Mini Mobile Telemetry System - On Ground Configuration Architecture

According to calculations, the expectation was to reach $26 \mathrm{~km}$ operational range in line of sight. It has was seen that the system could operate up to $30 \mathrm{~km}$ without data loss.

Second option for the system is to serve onboard in a flying test bed. A Grumman S$2 E / T$ model $A / C$ has been using as a flying test bed in Turkish Aerospace Industries Inc. For this scenario four receiving antennas (circular polarization) with LNAs planned to be fixed on the $A / C$ for real time data gathering. Antenna placement is planned to be mounted to the top of the front and rear fuselage and to the bottom of the front and rear fuselage. Antenna placement is shown on the figure below.

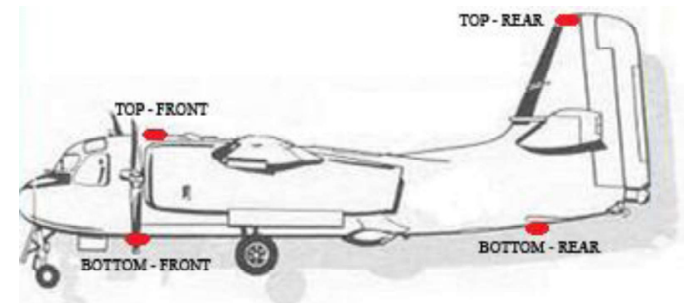

Figure 15 Receiving Antenna Placement

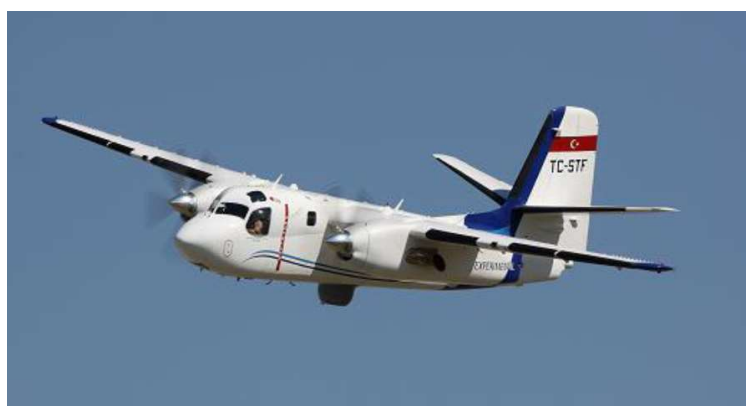

Figure 16 S2E/T - Flying Test Bed

RF switches are chosen to navigate the input signals to the receiver. All signal cables are chosen in low loss specifications and all cables are chosen manufactured of aluminum based materials to use the advantage of low weight and minimum bend radius. The system architecture for on board configuration is given below.

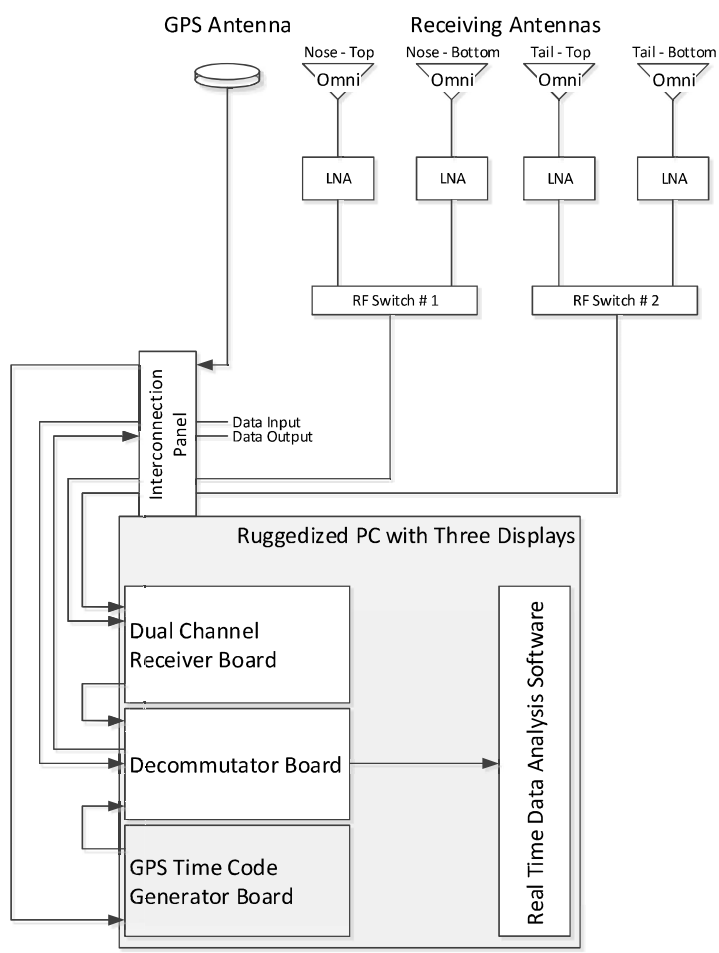

Figure 17 Mini Mobile Telemetry System - On Board Configuration Architecture

On board configuration allows flight test engineers to monitor the data flow of the $A / C$ under test from the chase $A / C$ (flying test bed). For the second option, three flight test engineers will be able to monitor the flight test parameters.

It has been evaluated that this configuration could be useful during long distance ferry flights that stationary telemetry systems range limits are exceeded. 
Third option for the system is to serve as a flying relay station in the flying test bed. For this scenario two transmitting antennas will be mounted on the $A / C$ additional to four receiving antennas described in second option.

Antenna placement and propagation analysis is shown below. The horizontal bar graph indicates the power level between $-240 \mathrm{dBm}$ to $-13 \mathrm{dBm}$.

Figure 18 Receiving Antenna Placement on S2-E/T Aircraft

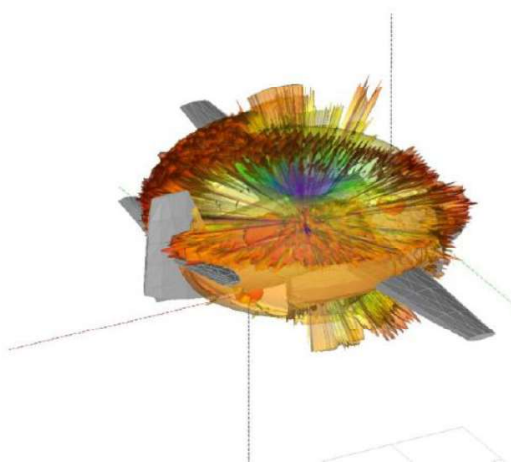

Figure 19 Farezone Analysis

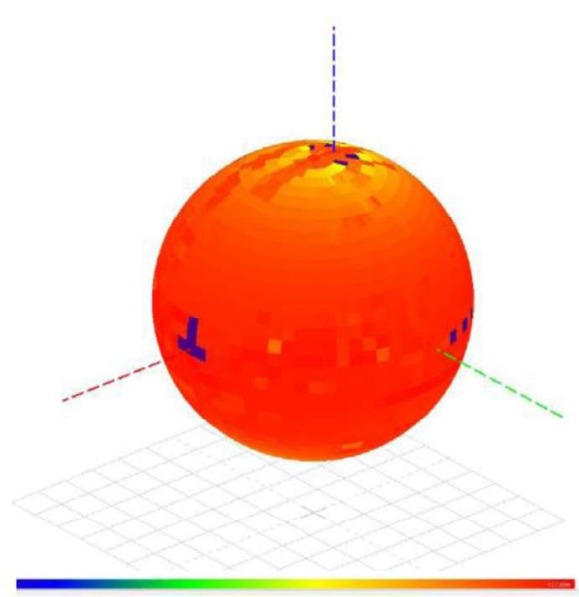

Figure 20 Total Power Analysis

For this option, the antenna of telemetry ground station will be tracing the chase $A / C$ which is the flying test bed instead of tracing the $A / C$ under test. Using the flying test bed as a relay station will allow the telemetry ground station to keep gathering data during flight tests which are performed out of line of sight such low altitude maneuvers.

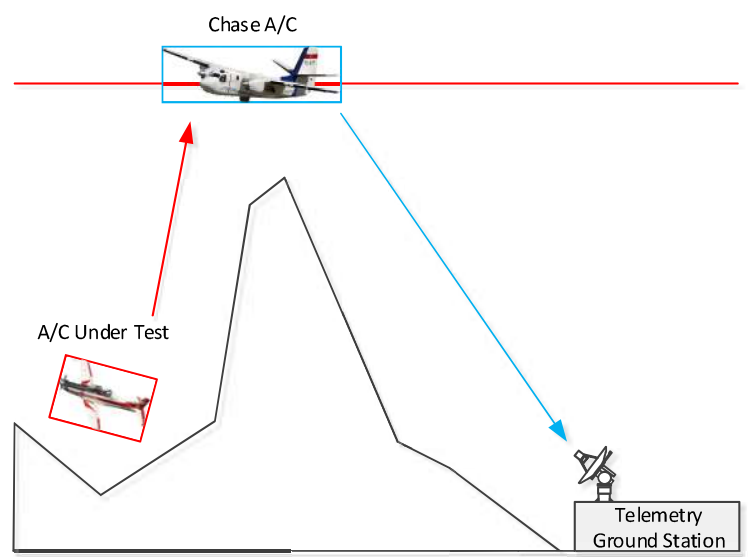

Figure 21 Flying Relay Station Figure

The system architecture for the flying relay station configuration is given below.

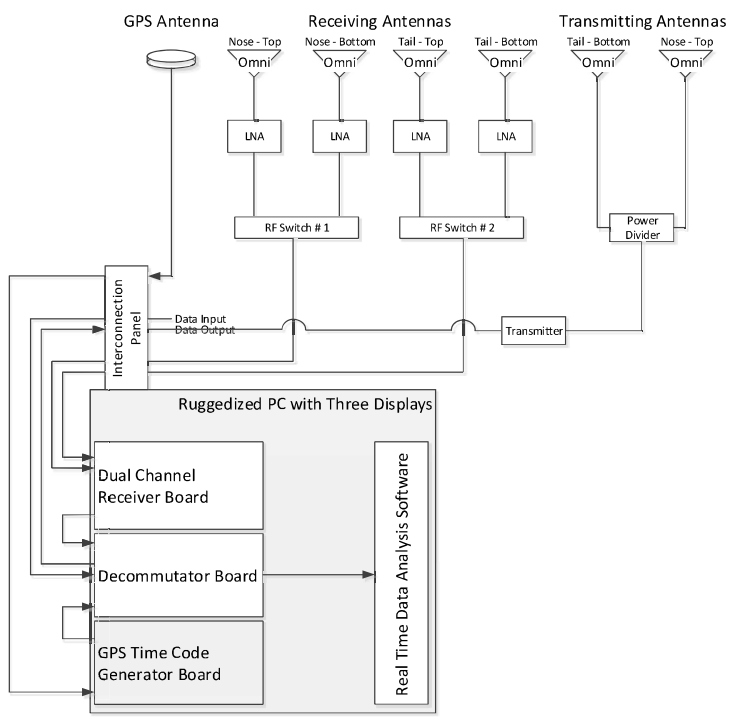

Figure 22 Mini Mobile Telemetry System - Flying Relay Station Configuration Architecture

It has been stated that Mini Mobile Telemetry System is a perfect alternative of huge ground stations due to its operational flexibility for mainly three different flight test operations. The first one is the flight tests which could be performed at close range and could be managed up to three flight test engineers on ground. The second one is the onboard configuration which could be used during long range flight tests or ferry flights so parameters gathered from the $A / C$ under test could be monitored in the chase $A / C$. The third one is the flying relay station configuration which transfers the gathered data packets from the $A / C$ under test to Telemetry Ground Station. 